\title{
Kreatiwiteit en Dead Poets Society: 'n kritiese evaluering
}

\author{
G.J. Rossouw \\ Departement Filosofie \\ Randse Afrikaanse Universiteit \\ JOHANNESBURG
}

\begin{abstract}
Creativity and Dead Poets Society: A critical evaluation

Although the need for the development of creative thinking is mentioned in the latest White Paper on education, not much has been done to enable teachers and lecturers to stimulate creativity in their classrooms. In this article, the film Dead Poets Society is used to explore central issues related to the development of creative thinking. The film is treated as a visual case study of Mr. Keating's approach to the development of creativity. In an analysis of the film his assumptions about creativity are retrieved, as well as the specific methods that he employed in order to stimulate creativity in his students. In the final part of the article a critical evaluation of his approach toward creativity is offered in which both strengths and weaknesses of his approach are exposed. By doing this the problems and challenges related to the development of creative thinking are explored.
\end{abstract}

\section{Inleiding}

Die film Dead Poets Society (DPS) nooi - of dwing - die kyker uit tot interpretasie. Vele interpretasies van die film is alreeds gewaag (vgl. Degenaar, 1989:6; Schoombie, 1989:2). In hierdie artikel sal die versoeking tot interpretasie van die film weerstaan word. Die film sal eerder ontgin word vir wat dit aan te bied het oor die ontwikkeling en bestuur van kreatiwiteit. Dit sal gedoen word aan die hand van bestaande literatuur oor kreatiwiteit. In dié opsig sal die film dus benut word as 'n gevallestudie oor kreatiwiteit.

Die motivering vir hierdie spesifieke wyse van omgang met die film is om kreatiwiteit op 'n praktykgerigte wyse krities te ondersoek. Die hantering van die film as ' $n$ gevallestudie bied juis hiertoe 'n geleentheid, aangesien 'n gevallestudie die leser/kyker dwing om self analiserend en beoordelend tot die praktyk van die gevallestudie toe te tree (kyk Donaldson et al., 1990:14). Daar sal onder meer aandag gegee word aan die volgende aspekte van die hantering van kreatiwiteit in die film: 
- Die teoretiese aannames onderliggend aan die benadering tot kreatiwiteit wat in die film gevolg word

- Die winspunte van die spesifieke benadering tot die ontwikkeling van kreatiwiteit.

- Die tekorte van die spesifieke benadering tot die ontwikkeling van kreatiwiteit.

Alvorens daar oorgegaan word tot hierdie analise van die film, sal 'n kort uiteensetting van die storielyn van die film gegee word ten einde die agtergrond van die analise te skets

Welton-kollege is 'n hoogaangeskrewe Amerikaanse skool wat daarop roem dat dit leerlinge voorberei vir toegang tot die beste Amerikaanse universiteite en sodoende vir beroepsukses. Die vier pilare wat voorgehou word as die basis vir die hoë aansien wat die skool geniet is: tradisie, eer, dissipline en uitnemendheid.

Aan die begin van die akademiese jaar word 'n oudleerling, John Keating, voorgestel aan die leerlinge as die nuwe Engels-onderwyser. Keating maak dit van die begin af duidelik dat hy van sy leerlinge verwag dat hulle vir hulself moet kan dink. Hy verbreek sodoende die benadering van slaafse en dikwels insiglose memorisering en reprodusering wat deur die meeste ander onderwysers in die skool gevolg word. In sy klasse dwing hy sy leerlinge tot kreatiwiteit. Hy moedig hulle ook aan om 'n vereniging wat gedurende sy skooljare bestaan het te laat herleef, naamlik die Dead Poet's Society (DPS). In sy tyd was die DPS gebruik as 'n geleentheid om gedigte voor te lees en met eie digpogings te eksperimenteer.

Sewe leerlinge gryp hierdie geleentheid aan en laat herleef DPS as 'n geheime vereniging. Hulle kom snags in 'n grot in die woud byınekaar en gee hulle eie karakter aan die DPS. Hulle ervaring in die DPS tesame met die stimulering wat hulle in Keating se poësie-klasse kry, het op sekere van die lede se lewens 'n beslissende invloed.

Die ervaring eindig in 'n tragedie as een van die lede van die DPS (Neill Perry) selfinoord pleeg, omdat sy pa hom nie wou toelaat om in 'n toneelstuk te speel nie. In 'n ondersoek wat volg op Neil se dood word die aktiwiteite van die DPS oopgevlek en deur die beheerraad van die skool as die oorsaak van Neill se dood aangedui. John Keating word verantwoordelik gehou vir die aktiwiteite van die DPS en sodoende ook indirek aanspreeklik gehou vir Neill se dood. As sondebok word hy gedwing om die skool te verlaat

In die slottoneel waar hy sy klaskamer ontruim, demonstreer 'n beduidende groep van die leerlinge in sy klas hulle waardering vir sy rol in die skool ten aansien van 
en tot onsteltenis van die skoolhoof. Sodoende daag hulle die hoof se gesag uit ten einde op 'n unieke wyse hulle eie stem te laat hoor.

Teen die agtergrond van hierdie erg kursoriese uiteensetting (wat geensins reg laat geskied aan 'n komplekse en gelaagde film nie), sal die beloofde analise van die film nou onderneem word.

\section{Onderliggende teorie}

Keating bied nêrens in die film 'n eksplisiete uiteensetting van sy verstaan van die proses van kreatiwiteit nie. Die onus is dus op die kyker om self die opvatting wat Keating se benadering tot kreatiwiteit onderlê, te ontsyfer. Hiervoor bied die film wel genoeg leidrade. Hierdie leidrade sal nagegaan en gebind word ten einde die teoretiese onderbou van sy benadering te rekonstrueer

Uit die analise van die film blyk dit dat Keating se verstaan van die ontwikkeling van kreatiwiteit rondom die volgende dimensies van kreatiwiteit gebou is:

- Motivering tot kreatiwiteit

- Deugde van die kreatiewe persoon

- Faktore wat kreatiwiteit ondergrawe

- Stimulering van kreatiwiteit

Elk van hierdie dimensies van sy benadering tot kreatiwiteit sal vervolgens in meer besonderhede bespreek word.

\subsection{Motivering tot kreatiwiteit}

Die ontwikkeling van kreatiwiteit begin by die bereidheid van die leerder om sy of haar kreatiewe denkvermoëns te ontwikkel. As die persoon nie glo dit is belangrik om sy/haar denke in hierdie verband te verbeter nie, is die kans baie gering dat sodanige ontwikkeling wel sal plaasvind. Die motivering van die potensiële leerder is daarom 'n voorwaarde wat vervul moet word alvorens die proses van ontwikkeling van kreatiewe vermoëns kan begin (vgl. Paul, 1993:16; Rossouw, 1994:4)

Keating was duidelik goed hiervan bewus: dit blyk uit die strategie wat hy volg om sy leerlinge te oortuig van die belang wat kreatiwiteit vir hulle het. Hy neem sy vertrekpunt in hulle skeptisisıne oor die relevansie van poësie vir hulle beroepsloopbane. As ambisieuse leerlinge wat hul oog het op beroepe wat vol is van beloftes van geld en aansien en waar effektiwiteit die wagwoord sal wees, kan hulle kwalik die relevansie van gedigte insien. Keating begin daarom om hul skeptisisme te ondergrawe deur aan te toon dat die lewe uit meer as bloot die 
Kreatiwiteit en Dead Poets Society: 'n kritiese evaluering

beoefening van ' $\mathrm{n}$ beroep bestaan. Hy wys hulle daarop dat die sin van die lewe nie net - of meestal nie - deur die beoefening van jou beroep verskaf of gewaarborg word nie. Die lewe verkry sy sin eerder in die emosionele tussenpersoonlike bindinge wat jy aangaan. Gedigte - of dan kreatiewe denke soos wat dit in die verstaan en skep van poësie gestalte vind - help jou juis om hierdie dimensie van die lewe te verken. Sy argument is dus dat kreatiwiteit nie irrelevant vir sy ambisieuse jong gehoor is nie, maar dat dit juis is wat hulle nodig het om 'n lewe vol kwaliteit te leef.

Die inneem van 'n positiewe disposisie teenoor denkontwikkeling kan daarom as die eerste been van Keating se teorie oor die ontwikkeling van kreatiewe denkvaardighede beskou word.

\subsection{Deugde van die kreatiewe persoon}

Vir kreatiwiteit om op die lange duur volgehou te word is meer nodig as 'n eenmalige oorreding om jou kreatiewe vernoëns te ontwikkel. Wat benodig word, is 'n verskuiwing van 'n eksterne lokus van kontrole oor kreatiwiteit na 'n interne lokus van kontrole oor kreatiwiteit. Die leerder moet dus nie telkens deur ' $n$ ander party van die belangrikheid van die ontwikkeling van denkvaardighede oortuig word nie, maar moet self die belang daarvan besef. Die bereidheid om kreatief te dink moet 'n permanente deel van jou persoonlike mondering word. Dit moet 'n denkdeug (trait of mind) word (vgl. Paul, 1993:259-262; Rossouw, 1994:6-10; Sternberg, 1992:122-127).

In aansluiting by Aristoteles (1976:91-110) kan deugde gedefinieer word as daardie aangeleerde disposisies wat jou optrede en besluite altyd beïnvloed. Waarop dit dan neerkom wanneer dit toegepas word op die ontwikkeling van kreatiwiteit, is dat dit tweede natuur vir jou sal raak om kreatief on te gaan met die uitdagings wat jy moet hanteer. Tipiese voorbeelde van sodanige kreatiewe denkdeugde is:

- Die bereidheid om die bestaande aannames uit te daag

- Die intellektuele moed om nuwe uitdagings aan te pak

- Die deursettingsvermoë om dubbelsinnigheid te kan deurstaan

- Die bereidheid om onmiddellike behoeftebevrediging uit te skakel

Dit is presies deugde soos hierdie wat Keating deurgaans in sy leerlinge probeer kultiveer het. Regdeur die film herinner hy sy leerlinge dat hulle selfstandig moet word en hulle nie moet uitlewer aan oorheersing deur die groep nie. Hy verwoord hierdie oproep van hom op 'n verskeidenheid van wyses. Soms sê hy dit eksplisiet vir hulle: "Learn to think for yourself". Ander kere verwoord hy dit 
meer beeldend: "Life is a poem, and you can contribute a verse", of "You should learn to find your own voice". Deurentyd probeer hy sy leerlinge oortuig dat hulle oor waardevolle idees beskik. Hulle moet net bereid wees om hulle verbeelding te gebruik ten einde hierdie waardevolle idees vry te stel. Sodoende skep hy gaandeweg by hulle ' $n$ instelling of ' $n$ houding wat hulle bereid maak om te waag en te eksperimenteer en nie die bestaande sonder meer as vanselfsprekend te aanvaar nie.

Die belang van denkdeugde in volgehoue kreatiwiteit kan kwalik oorskat word. Solank kreatiwiteit van eksterne motivering afhang, staan dit steeds die gevaar om te verdwyn sodra die bron van eksterne motivering verdwyn. Wanneer die nodige denkdeugde egter gekultiveer is, word kreatiwiteit 'n lewenswyse, aangesien die deugde jou steeds disposisioneer om op 'n kreatiewe wyse met jou uitdagings om te gaan. Jou kreatiwiteit hang nie meer van die goedkeuring of ondersteuning van ander af nie, maar van 'n eie wilsbesluit (vgl. Amabile, 1983:370-372).

\subsection{Faktore wat kreatiwiteit ondergrawe}

Keating se benadering tot die ontwikkeling van kreatiwiteit word verder gekenmerk deur die moeite wat hy doen om sy leerlinge bewus te maak van die inhiberende invloed wat sekere faktore op hulle het. Hy probeer hulle veral bewus maak van die rol wat sekere stereotiepe maniere van handeling (of gewoontes) op hulle het. Kundiges oor kreatiwiteit is dit eens dat die menslike brein 'n patroonskeppende geneigdheid het (De Bono, 1990:27-28; Caine \& Caine, 1990:67). Wanneer 'n probleem 'n aantal kere suksesvol op 'n sekere wyse gehanteer is, word daardie spesifieke hanteringswyse in die brein vasgelê as 'n patroon vir die hantering van soortgelyke probleme in die toekoms. Ten einde kreatief te kan optree, moet jy eers bewus word van die inhiberende effek wat jou aangeleerde gewoontes op jou kreatiewe vermoë het (vgl. Evans, 1991:48-49). Jy moet dan verder ook bereid wees om jou gewoontes uit te daag ten einde jou patroonmatige optrede te deurbreek.

Keating en ook die regisseur bring die leerlinge en die kyker telkens onder die indruk van die mens se geneigdheid tot konformering aan die bekende. Keating illustreer dit onder andere in die toneel waar hy eers drie leerlinge op hulle eie tempo om 'n vierkant laat stap. Dan motiveer hy die res van die klas om saam ritmies hande te klap. Die gevolg is dat die drie in-'n-sirkel-stappende leerlinge kort voor lank die ritme volg wat vir hulle geklap word deur die res van die klas. Die regisseur maak ook telkens van tonele gebruik waar konformiteit uitgebeeld word. In dié opsig benut hy tonele waarin sirkels voorkom baie doeltreffend. Hy wys byvoorbeeld 'n toneel waar die leerling op 'n sirkeltrap in die skool al in die rondte op en af beweeg. Daar is beweging maar geen vernuwing nie. Ook by die vergadering van die DPS verval die sogenaamde "kreatiewes" kort voor lank in 
'n nuwe vorm van konformiteit wat weereens deur die regisseur uitgebeeld word in 'n toneel waar die lede van die DPS in 'n sirkeldans opgeneem word. Die groot swerm voëls wat die regisseur by geleentheid wys, sinspeel bes moontlik ook op die kuddementaliteit wat konformiteit aan bekende gewoontes tot gevolg het. Al die beelde van konformiteit word deur die regisseur benut om aan te dui dat die sterk klem op tradisie in Welton Kollege omgeslaan het van 'n positiewe krag tot 'n verslawende dwang wat kreatiwiteit inhibeer.

Bewuswording van die inhiberende effek wat gewoontes of stereotiepe gedrag het, is soos reeds gestel is baie belangrik. Om die krag van sodanige gewoontes te ontkom, verg besondere inspanning. Juis daartoe wil Keating sy leerlinge motiveer.

Gewoontes is egter nie die enigste faktor wat kreatiwiteit kan inhibeer nie. Daar is ook ander faktore wat deur Keating aan sy leerlinge uitgewys word. So dui hy byvoorbeeld aan dat slaafse navolging van outoriteite verbeelding kan doodmaak. Tydens een van sy eerste ontmoetings laat hy sy leerlinge die inleiding uit hulle voorgeskrewe handboek uitskeur. Die inleiding is geskryf deur 'n sogenaamde kenner van die poësie wat oor 'n doktorsgraad beskik. Keating dwing egter sy leerlinge om hierdie outoriteit uit te daag deur sy woorde letterlik te vernietig. Die leerlinge skeur die bladsye uit, frommel dit op en gooi dit in 'n snippermandjie.

Keating maak sy leerlinge verder daarvan bewus dat daar ook intra-persoonlike faktore is wat hulle kreatiwiteit kan ondergrawe, soos byvoorbeeld hulle vrees om te fouteer of hulle vrees dat hulle hulself belaglik sal mak voor hulle vriende. In een toneel dwing hy letterlik die teruggetrokke Todd Anderson om sy vrees vir selfvernedering te oorkom deur hom ten aansien van die hele klas te dwing om sy verbeelding te gebruik. Na die episode het Todd inderdaad die intra-persoonlike struikelblok oorkom en raak hy meer gemaklik en gewaagd met sy kreatiwiteit.

Bewusmaking van die faktore wat kreatiwiteit inhibeer, verteenwoordig die een kant van kreatiwiteit. Die ander kant van die ontwikkeling van kreatiwiteit het te make met die positiewe stappe wat geneem kan word ten einde kreatiwiteit te stimuleer. Die aannames en voorveronderstellings waarop hy sy stimulering van kreatiwiteit gegrond het, sal vervolgens uitgewys word. Daar sal ook aangetoon word hoe die verskillende tegnieke wat hy benut het, hierdie onderliggende beginsels van kreatiwiteit illustreer.

\subsection{Stimulering van kreatiwiteit}

Kreatiwiteit kan nie deur die toepassing van 'n tegniek gewaarborg word nie; tog is daar verskeie tegnieke wat benut kan word on persone tot kreatiwiteit te stimuleer. Kreatiewe tegnieke is niks anders nie as 'n vorm van intellektuele 
Gedeon J. Rossouw

taktiek wat die waarskynlikheid van die generering van innoverende idees verhoog. Die waarde van sulke tegnieke in die generering van innoverende idees is reeds navorsingsmatig bewys (Perkins, 1986:4-5; Amabile, 1983:364-365).

Die tegnieke wat vir hierdie doel benut kan word, is gebaseer op bepaalde aannames oor kreatiwiteit. Dit is om dié rede belangrik om verby die spesifieke formaat van 'n tegniek te kan kyk en te kan bepaal wat die aanname is waarop die tegniek gebaseer is. Wanneer die aanname verstaan word, word die tegniek deursigtig.

In die film kan daar ten minste drie sodanige aannames oor kreatiwiteit geïdentifiseer word - aamnames wat ten grondslag lê aan die verskillende tegnieke wat in die film benut word om kreatiwiteit te stimuleer. Elkeen van hierdie aannames sal vervolgens aan die orde gestel word. Insake elke aanname sal dan aangetoon word hoe die teoretiese aanname tot 'n praktiese tegniek geïmplimenteer is.

'n Eerste aanname is dat kreatiwiteit gestimuleer word wanneer 'n ongewone relasie tussen konsepte of fenomene geskep word. Wanneer so 'n ongewone relasie geskep word, maak die relasie meestal nie onmiddellik sin nie. Die persoon wat met so 'n ongewone relasie gekonfronteer word, word dan gedwing om $\sin$ te maak uit die skynbare onsimigheid. Dit vereis ' $n$ verbeeldingryke denkgreep ten einde sin te skep, en sodoende word kreatiwiteit gestimuleer. Dit is opvallend dat die meeste innoverende idees nie uit die niet geskep word nie, maar juis die resultaat is van die kombinering van bestaande, maar skynbaar onverwante idees of voorwerpe. Die tegniek wat op grond van hierdie aanname ontwikkel is, staan bekend as die tegniek van gedwonge assosiasie (Grossman \& Wiseman, 1993:9; De Bono, 1990:169).

Keating benut 'n spesifieke variant van die tegniek van gedwonge assosiasies, naamlik vrye assosiasie. In 'n sentrale toneel in die rolprent dwing hy vir Todd om sy vrees vir kreatiewe skepping te oorkom. Hy wys vir hom 'n foto teen die muur van die klaskamer en druk daana sy oè toe en vra hom watter indrukke die foto by hom losmaak. Nadat Todd die losstaande indrukke genoem het, motiveer Keating hom om die indrukke te kombineer en dan in terme van die kombinasie van indrukke voort te gaan om poësie te skep. Na aanvanklike stamelings begin die tegniek van vrye assosiasie vir hom te werk en lewer Todd sy eerste skeppende werk in die klas.

'n Verdere voorbeeld van gedwonge assosiasie is Keating se benutting van gedigte en klassieke musiek tydens 'n sokkeroefening. By die besondere sokkeroefening deel hy vir elke leerling 'n versreël uit 'n gedig uit. Terwyl hy dan klassieke musiek op die sokkerveld speel, moet die leerlinge eers die versreël hardop voorlees en direk daama die sokkerbal skop. Die geamuseerdheid 
waarmee sy sokkerspan hom aanvanklik gadeslaan, getuig daarvan dat hy weereens daarin geslaag het om hul vertroude raamwerk te deurbreek. Poësie, klassieke musiek en sokker het in hul bestaande verwysingsraamwerk niks met mekaar te make nie. Deur die drie onverwante fenomene op mekaar af te forseer, skep dit die geleentheid om selfs iets soos 'n sokkeroefening op 'n nuwe wyse aan te pak

'n Tweede aanname is dat kreatiwiteit gestimuleer word wanneer 'n bekende saak vanuit 'n ongewone hoek of perspektief bekyk word (Grossman \& Wiseman, 1993:1). Ten einde die suigkrag te ontkom wat jou gewone wyse van probleemhantering (gewoontes) op jou het, moet jy uit jou normale verwysingsraamwerk of gedragspatrone gedwing word. Die blootstelling aan 'n ongewone perspektief op sake verhoog die moontlikheid om uitdagings op 'n ongewone (ongewoonte) wyse te hanteer. Sodoende ontstaan die moontlikheid dat bestaande denk- en handelingspatrone deurbreek kan word en nuwe patrone gevorm kan word. Dit volg uiteraard vanselfsprekend dat nuwe patrone wat sodoende gevorm word, eweneens die potensiaal tot stereotiepe gedrag het.

Keating maak van ' $n$ verskeidenheid tegnieke gebruik om sy leerlinge uit hulle bestaande kyk op sake te dwing. Die onderstaande drie voorbeelde toon aan hoe hy daarin slaag om sy leerlinge te konfronteer met die onverwagse en hulle sodoende uit te nooi om hulle geykte denk- en gedragspatrone te deurbreek.

Keating maak telkens van onkonvensionele posisionering gebruik om sy leerlinge uit hulle gewone gedrag te lok. Wanneer hy byvoorbeeld die eerste dag die klas binnekom, gaan staan hy agter die klas, in plaas van voor hulle soos almal gewoond was. By 'n ander geleentheid hurk hy weer op die vloer van die klas en dwing sodoende almal om af te buig na hom toe. Dan staan hy weer bo-op sy tafel voor in die klas. In al drie die gevalle vang hy sy leerlinge onkant, want sy ongewone posisionering plaas ook sy leerlinge tegelykertyd in 'n ongewone posisie. Hulle sien hul onderwyser vanuit ' $n$ ander perspektief as waaraan hulle gewoond is. Dit dwing hulle om hulle opnuut ten opsigte van die onderwyser te oriënteer. Sodoende deurbreek hulle hul nonnale klasgedrag en sien sodoende dinge raak wat andersins ongesien sou gebly het.

'n Derde aanname oor kreatiwiteit wat in die film sigbaar is, is dat nuwe idees dikwels gebore word wanneer die teenoorgestelde posisie as die een waarin jy wil wees, verken word. Wanneer daar in die teenoorgestelde rigting beweeg word, word jy weereens gedwing om 'n saak vanuit 'n ongewone perspektief te bekyk. Die tegniek van teenoorgesteldes is uit hierdie aanname oor kreatiwiteit ontwikkel (Thompson, 1992:89-94; De Bono, 1990:124-126).

Keating benut die tegniek van teenoorgesteldes om sy leerlinge te dwing om nuut na sake te kyk. Tydens sy eerste klas konfronteer hy die klomp lewenslustige 
jong seuns met die teenoorgestelde van jonkwees, naamlik die aftakeling en vernietiging wat die ouderdom en uiteindelik die dood meebring. Hy doen dit deur hulle fyn te laat kyk en "luister" na dit wat die ou vergeelde foto's van reeds gestorwe oudleerlinge van die skool vir hulle mee te deel het. Deur hulle te konfronteer met die dood wat totaal buite hulle nornale verwysingsraamwerk van jonk-en-ambisieus-wees val, slaag hy eweneens daarin om hulle te ontsenu en op 'n nuwe wyse na sake te laat kyk. Via die konfrontasie met die dood open hy vir hulle nuwe perspektiewe op die uniekheid en geleenthede van die jeug.

'n Vierde aanname oor kreatiwiteit wat ook skrams in die fliek geopenbaar word, het te make met perseptuele openheid. Perseptuele openheid verwys na die moontlikheid om 'n saak of voorwerp nie net op een manier te sien nie, maar meerdere moontlikhede in 'n saak of voorwerp raak te sien (Amabile, 1983:364; Evans, 1991:50). Die teenoorgestelde van perseptuele openheid is perseptuele fiksasie; dit is wanneer daar slegs een perspektief of gebruiksmoontlikheid raakgesien kan word. Sodanige fiksasie inhibeer kreatiwiteit uiteraard. Wanneer daar egter perseptuele openheid is, word alternatiewe moontlikhede in bestaande konsepte of dinge raakgesien.

In die film illustreer een van Keating se leerlinge, Neill Perry, die werking van perseptuele openheid. Wanneer Todd Anderson terneergedruk en ongelukkig is ondat sy ouers vir die tweede agtereenvolgende jaar vir hom presies dieselfde geskenk vir sy verjaarsdag gegee het, naamlik 'n lessenaarstel, kom Neill tot sy redding. Neill oorreed hom om die ander moontlikhede in die lessenaarstel raak te sien, soos dat dit ook lyk soos 'n vlieënde voorwerp. Wanneer Todd die moontlikheid insien, weet hy ook wat on met die lessenaarstel te maak en sodoende sy teleurstelling te oorkom. Hy en Neill laat die lessenaarstel van die gebou af vlieg as "the world's first unmanned flying desk set!"

\subsection{Samevatting}

Samevattend kan dus gesê word dat Keating se benadering tot die ontwikkeling van kreatiwiteit die volgende dimensies openbaar: Die ontwikkeling van kreatiewe potensiaal kan eers geskied wanneer 'n persoon die regte disposisie of motivering vir denkontwikkeling het. Hierdie motivering wat aanvanklik mag begin op die insiatief van 'n ander party, moet uiteindelik geïnternaliseer word in die vorm van denkdeugde ten einde volgehoue kreatiwiteit te verseker. Naas motivering vereis kreatiwiteit ook dat persone bewus sal wees van hulle geneigdheid tot konformering as gevolg van gewoontes, asook van ander faktore wat hulle kreatiwiteit kan inhibeer. Die moontlikheid om stereotiepe gedrag te deurbreek, word verhoog wanneer die persoon via spesifieke tegnieke gestimuleer word tot nuwe perspektiewe op die bestaande. 
Kreatiwiteit en Dead Poets Society: 'n kritiese evaluering

Vervolgens sal gekyk word na winspunte en tekorte in die wyse waarop spesifiek Keating die ontwikkeling van kreatiwiteit benader het.

\section{Winspunte}

Die grootste winspunt van Keating se benadering tot kreatiwiteit lê in sy multidimensionele benadering. Hy toon duidelik dat kreatiwiteit om meer gaan as bloot die aanleer van ' $n$ aantal tegnieke om kreatiwiteit te stimuleer. Wanneer die ontwikkeling van kreatiwiteit slegs die aanleer van kreatiewe tegnieke behels, het dit min waarde, aangesien die oordrag van die tegnieke na ander terrreine van die lewe dan gewoonlik swak is. As die tegnieke nie ondersteun word met insig in die tegnieke, en met motivering tot kreatiwiteit en 'n kreatiewe ingesteldheid nie, word sodanige tegnieke se waarde erg gedevalueer (Tinzmann et al., 1992:189190).

Juis om dié rede is die moeite wat Keating gedoen het om 'n kreatiewe gesindheid (denkdeugde) by sy leerlinge te kultiveer, asook sy pogings om hulle insig te gee in die belangrikheid van kreatiwiteit (motivering) beslis 'n bate in sy benadering. Ook die feit dat hy aandag gee aan struikelblokke in die weg van kreatiwiteit bevestig sy multidimensionele benadering tot kreatiwiteit.

'n Verdere winspunt in Keating se benadering is die feit dat hy dit wat hy vir sy leerlinge geleer het, ook self gemodelleer het. Hy het nie net sy leerlinge aangespoor om die bestaande idees uit te daag nie, maar het dit self ook gedoen. In die opsig het hy vir hulle 'n voorbeeld gestel ten opsigte van die deugde waaroor 'n kreatiewe denker moet beskik. Hy het byvoorbeeld die intellektuele moed geopenbaar om die onderrigbenadering van Welton College, waarvan hyself as oudleerling 'n produk was, uit te daag. Hy het getoon dat hy nie maklik geïntimideer raak as ander hulle goedkeuring van hom weerhou nie, soos wat sy kollegas en die hoof van die skool inderdaad gedoen het. Verder het hy ook die nodige intellektuele deursettingsvernoë geopenbaar om sy benadering ten spyte van teenstand van sy kollegas vol te hou. Miskien was sy grootste bate in hierdie opsig die openlike genot wat hy uit die skep van nuwe idees geput het. Dit was juis hierdie genot wat aansteeklik en bykans onweerstaanbaar deurgewerk het na sy leerlinge toe

\section{Tekorte}

In 'n analise van Keating se benadering tot kreatiwiteit kan daar egter vele tekorte uitgewys word. Vier van die belangrikste gebreke in sy benadering tot kreatiwiteit sal vervolgens uitgewys word.

'n Eerste tekort in Keating se benadering was sy oorbeklemtoning van kreatiewe denke sonder om ook terselfdertyd die kritiese denkverınoë van sy leerlinge te 
Gedeon J. Rossouw

stimuleer. In dié opsig was hy net nog 'n slagoffer van die valse teenstelling tussen kreatiewe en kritiese denke (Bailin, 1987:25; Paul, 1993:10; Gilhooley, 1988:174). Kreatiewe denke wat nie gerugsteun word deur kritiese denke nie kan ontaard in sinlose uitdaging sonder dat dit werklik enige vernuwing tot gevolg het. Dit is belangrik om in ag te neem dat egte kreatiwiteit altyd die eienskap van verbetering moet openbaar. Indien die spesifieke eienskap afwesig is, kan kreatiwiteit ontaard in verandering ter wille van verandering of in blote roekeloosheid. As gekyk word na veral die optrede van Charlie, wat homself later vernoem het na Niwanda, is dit duidelik dat sy sogenaamde kreatiwiteit ontbreek aan die eienskap van verbetering. Dit word veral goed geillustreer in die skoolsaal-episode waar hy die hoof se gesag uitdaag sonder om enigsins iets konstruktiefs daarmee te bereik. Keating self het dit na die voorval nodig gevind om sy optrede as dwaasheid af te maak toe hy gesê het: "There is a time for daring and a time for caution, and wise men know the difference."

'n Tweede tekort in Keating se benadering is sy nalaat om die etiese implikasies van kreatiwiteit te beklemtoon. Kreatiwiteit veronderstel vemuwing en vernuwing impliseer weer aanpassing by veranderende omstandighede. Innovering behoort daarom aangepak te word in die besef dat dit implikasies het vir ander mense wie se onstandighede deur die verandering geraak gaan word. Dit beteken geensins dat innovering liewer gelaat moet word, omdat dit aanpassing van ander gaan verg nie. Dit beteken slegs dat innovering gedoen moet word met die inagneming van ander se belange.

Daar is verskeie voorbeelde in die film wat hierdie tekort in Keating se benadering oopvlek. Charlie se optrede teenoor die meisie waarop hy verlief raak, te wete Chris, illustreer hierdie gebrek aan sensitiwiteit. In sy drif om nie die bestaande situasie sonder meer te aanvaar nie, maar dit uit te daag, doen hy die meisie op wie hy verlief is juis skade aan. Dit gebeur wanneer hy ten aanskoue en ten aanhore van haar klasmaats en teen haar wil vir haar hardop 'n liefdesgedig voorlees. Sy ervaar dit geensins as vleiend nie, maar veel eerder as 'n vernedering.

Keating self maak hom ook skuldig aan dieselfde gebrek aan morele sensitiwiteit in sy optrede teenoor Todd. Dit gebeur wanneer Todd met hom kom praat oor sy pa se verbod op sy verdere deelname aan die toneelstuk waarin hy die hoofrol speel. Keating moedig hom aan om nie sy pa se verbod te aanvaar nie, maar dit uit te daag. Todd probeer dan om vir Keating te verduidelik dat sy pa geensins oop is vir oortuiging nie, maar sonder enige sukses. Keating hou voet by stuk en dring daarop aan dat Todd sy pa tot ander insigte moet bring. Ten einde te ontkom aan die dilemma waarin hy hom bevind, naamlik dat hy aan die een kant wil voortgaan met sy toneelspel, maar terselfdertyd nie kans sien om sy pa te konfronteer oor die verbod wat hy op sy verdere deelname aan die toneelstuk 
Kreatiwiteit en Dead Poets Society: 'n kritiese evaluermg

geplaas het nie, besluit Neill om vir sy pa te lieg. Hierdie leuen loop uiteindelik uit op 'n fiasko wanneer sy pa uitvind dat hy deur Neill bedrieg is. Die fiasko eindig in Neill se selfmoord.

Hierdie episode weerspieël tegelyk ook 'n derde tekort in Keating se benadering, naamlik dat hy by meer as een geleentheid sommige van sy leerlinge gedwing het tot kreatiwiteit. Dit is altyd 'n baie riskante benadering, aangesien gedwonge kreatiwiteit per definisie ekstern gemotiveer is. Navorsing het aangetoon dat kreatiwiteit wat ekstern gemotiveer is, ongewens is om twee redes. Enersyds lewer dit swakker resultate as in gevalle waar kreatiwitieit intern gemotiveer is en andersyds word kreatiwiteit gestaak wanneer die bron van eksterne motivering nie meer aanwesig is nie (Amabile, 1983:370-372; Tinzmann et al., 1992:208209; Torrance, 1994:55).

Tweedens is kreatiwiteit wat afgedwing word ook riskant, aangesien dit die persoon wat tot kreatiwiteit gedwing word, ongemaklik kan maak oor sy of haar kreatiwiteit. Veral wanneer die eksterne dwang tot kreatiwiteit verleentheid veroorsaak vir die persoon wat tot kreatiwiteit gedwing word, kan dit die persoon ongemaklik laat en van sy of haar kreatiwiteit vervreem. Die toneel in die film waar Keating vir Todd dwing om teen sy sin en ten aanskoue van al sy klasmaats skeppend te dink, kon baie maklik in 'n verleentheid vir Todd ontaard het. In die film het die dwang van Keating op Todd geluk, maar daar is geen waarborg daarvoor dat dit in alle gevalle so 'n gelukkige einde sal hê nie. Dit is belangrik dat kreatiwiteit altyd so ontwikkel sal word dat dit persone gemaklik laat voel oor hulle kreatiwiteit ten einde juis sodoende hulle kreatiwiteit te versterk.

'n Laaste tekort van Keating se benadering tot kreatiwiteit is geleë in die feit dat hy nie sy leerlinge voorberei het vir die konsekwensies van kreatiwiteit nie. Om kreatief te wees is baie opwindend, maar dit is ook tegelyk baie riskant. Kreatiwiteit bevraagteken die bestaande manier van dinge doen en dikwels ook die bestaande (aanvaarde) orde. Dit spreek daarom vanself dat kreatiwiteit die wat belang het by die bestaande orde, of dié wat hulle veilig voel in die bestaande orde, gaan ontstel. Keating het sy leerlinge gestinuleer tot kreatiwiteit sonder om hulle voor te berei op die prys wat hulle kon betaal vir hulle kreatiwiteit. Daar is iets immoreels daarin om mense op 'n roete te stuur sonder om hulle te waarsku oor die risiko's verbonde aan die spesifieke roete.

Wat sy benadering tot kreatiwiteit in dié opsig besonder kwesbaar maak, is dat hy kreatiwiteit in een subsisteem van die skool gestimuleer het, sonder om ook die ander subsisteme in die skool te probeer verander. Hierdie benadering moes noodwendig lei tot spanning tussen die verskillende subsisteme in die skool. Dit is nie verkeerd om ' $n$ sisteem van onder af te onvorm deur by een subsisteem te begin in die hoop dat verandering in een subsisteem ook ' $n$ invloed op die ander subsisteme mag hê nie. Wat wel verkeerd was van Keating, was om nie sy 
leerlinge te waarsku oor die gevolge wat lulle kreatiwiteit in een subsisteem van die skool vir hulle kon inhou nie. In dié opsig het Keating se fout nie in sy stimulering van kreatiwiteit gelê nie, maar wel in sy gebrek aan die bestuur van kreatiwiteit.

\section{Konklusie}

Die ontwikkeling van kritiese en kreatiewe denke het 'n hoë prioriteit in SuidAfrika geword, soos ook in die res van die wêreld. In die Witskrif oor Onderwys van 1994 word daar eksplisiet gesê dat: "the curriculum and teaching methods should encourage independent and critical thought" (p. 12). Daar is egter nog nie veel gedoen ten opsigte van die besinning oor hoe hierdie kritiese en kreatiewe denkvaardighede ontwikkel en onderrig moet word nie. Naas die ander interpretasie- en ontginningsmoontlikhede wat die film Dead Poets Society bied, het bostaande analise getoon dat die film sigself baie goed leen vir onderrigmateriaal in hierdie verband mits dit as 'n gevallestudie oor kreatiwiteit benader word. Die waarde van die film lê nie soseer daarin dat dit as ' $n$ ideaal of model voorgehou kan word nie, maar juis die gebreke ten opsigte van die ontwikkeling van kreatiwiteit in die film nooi die kyker uit on self na te dink oor die stimulering van kreatiwiteit. Dead Poets Society kan sodoende lewe gee aan die besinning oor die onderrig van kreatiwiteit.

\section{Bibliografie}

ARISTOTELES. 1976 The Nichomachean ethics. London : Penguin Books.

AMABILE, T.M 1983 The social psychology of creativity: A componential conceptualization Journal of Personality and Social Psychology, 45(2):357-376.

BAILIN, S. 1987. Critical and creative thinking. Informal Logic, 9(1):23-30

CAINE, R.N \& CAINE, G. 1990. Understanding a brain-based approach to learning and teaching. Fdicalional Leadership, 68(2):66-70.

DE BONO, E. 1990 Lateral thinking. London : Penguin Books

DEGENAAR, J. 1989. Interbetreklikheid van lewe en dood. Beeld, Kalender: 6, Nov 15

DONALDSON, T. \& GINI, A.R. 1990 Case studies in business ethics. New Jersey Prentice Hall

EVANS, J R 1991. Creative thinking in the decision and management sciences. Cincinatti : South Western Publishing Company.

GILHOOLEY, K.J 1988. Thinking: directive, undirective and creative. London : Academic Press.

GROSSMAN, S.R. \& WISEMAN, E.E 1993 Seven operating principles for enhanced creative problem solving training Journal of Creative Behavior, 27(1):1-17.

PERKINS, D.N. 1986. Thinking frames. Fiducational Leadership, 63(8) 4-10

PAUL, R. 1993. Critical thinking. Sonoma, Ca. : Foundation for critical thinking.

ROSSOUW, G.J. 1994. Skilful thinking. Pretoria : HSRC Press.

SCHOOMBIE, S. 1989 Weir gryp die dag met Dead Poe's Beeld, Kalender: 2, Okt 13

STERNBERG, R.J. 1992. Creativity, critical reasoning, and the problem of contentorientated education. (In Talaska $e d$. Critical reasoning in contemporary culture. Albany : State University of New York Press p 113-131.) 
Kreatiwiteit en Dead Poets Society: 'n kritiese evaluering

THOMPSON, C.C. 1992. What a great idea New York: Harper Perennial.

TINZMANN, M \& JONES, B.F 1992. Changing societal needs: Changing how we think about curriculum and instruction. (In Collins, C \& Mangieri J.N Teaching thinking London : Lawrence Erlbaum Associates Publishers p 185-220)

TORRANCE, P 1994. Creativity: Just wanting to know. Pretoria : Benedic Books 